\title{
SENTIMENTOS DESPERTADOS EM FAMILIARES DE PESSOAS INTERNADAS NA UNIDADE DE TERAPIA INTENSIVA
}

\author{
Vanessa Maria Spohr ${ }^{1}$, Hilda Maria Barbosa de Freitas², Silomar Ilha ${ }^{3}$, Glaucia Dal Omo Nicola ${ }^{4}$, \\ Claudia Zamberlan ${ }^{5}$, Maria Helena Gehlen ${ }^{6}$
}

RESUMO: Trata-se de uma pesquisa exploratória, descritiva, de caráter qualitativo, desenvolvida com oito familiares de pessoas internadas na Unidade de Terapia Intensiva de um hospital de médio porte localizado na região central do Rio Grande do Sul, no período de agosto e setembro de 2010, que objetivou conhecer os sentimentos despertados em familiares em relação ao ambiente e aos profissionais de saúde. Os dados, coletados por meio de entrevista semiestruturada, foram analisados pelo método de análise de conteúdo e do qual emergiram as categorias Impotência frente à hospitalização do familiar, Insegurança relacionada à proximidade com morte, Inflexibilidade da equipe de saúde diante dofamiliar, e Ausência de diálogo comos familiares. Ocuidado aos familiareséumanecessidade que deve se estender do desenvolvimento profissional para o cotidiano do serviço dos profissionais. Assim, torna-se possível auxiliar os familiares no enfrentamento da doença e adaptação da hospitalização, desmistificando a associação deste ambiente ao evento da morte. DESCRITORES: Família; Unidade de terapia intensiva; Sentimentos; Enfermagem.

\section{FEELINGS AROUSED IN THE FAMILIES OF PEOPLE HOSPITALIZED IN INTENSIVE CARE UNITS}

\begin{abstract}
This is exploratory, descriptive research with a qualitative character, undertaken with eight family members of persons hospitalized in the Intensive Care Unit of a medium-size hospital located in the central region of Rio Grande do Sul, in the period August - September 2010, which aimed to investigate the feelings aroused in family members in relation to the environment and the health professionals. The data, collected through semi-structured interviews, was analyzed using the method of content analysis, from which emerged the categories Impotence in the face of the familymember's hospitalization, Insecurity related to the closeness of death, Inflexibility of the health team regarding the family member, and Absence of dialog with the family members. The care for the family members is a need which must extend from professional development to the professionals' routine work. Thus, it becomes possible to assist the family members in coping with the illness and adapting to the hospitalization, demystifying the association of this environment with the event of death. DESCRIPTORS: Family; Intensive Care Unit; Feelings; Nursing.

\section{SENTIMIENTOS DESPERTADOS EN FAMILIARES DE PERSONAS INTERNADAS EN LA UNIDAD DE TERAPIA INTENSIVA}

RESUMEN: Esta es una investigación exploratoria, descriptiva, de carácter cualitativo, desarrollada con ocho familiares de personas internadas en la Unidad de Terapia Intensiva de un hospital medio, ubicado en la región central de Rio Grande do Sul, en el período de agosto a septiembre de 2010, cuyo objetivo fue conocer los sentimientos despertados en familiares acerca del ambiente y de los profesionales de salud. Los datos, obtenidos por medio de entrevista semiestructurada, fueron analizados por el método de análisis de contenido, y del cual resultaron las categorías Impotencia delante de la hospitalización del familiar, Inseguridad relacionada a la proximidad de la muerte, Inflexibilidad del equipo de salud delante del familiar, y Ausencia de diálogo con los familiares. El cuidado a los familiares es una necesidad que debe se extender del desarrollo profesional para el cotidiano del servicio de os profesionales. De ese modo, se vuelve posible ayudar los familiares en el afrontamiento de la enfermedad y adaptación de la hospitalización, desmitificando la asociación de este ambiente al evento de la muerte.

DESCRIPTORES: Familia; Unidad de terapia intensiva; Sentimientos; Enfermería.

\footnotetext{
${ }^{1}$ Enfermeira. Acadêmica do Curso de Psicologia do Centro Universitário Franciscano.

${ }^{2}$ Enfermeira. Mestre em Enfermagem. Doutoranda em Enfermagem pelo DINTER Novas Fronteiras UNIFESP/UFRJ/UFSM. Professora da UNIFRA. Membro do Grupo de Estudos e Pesquisa em Empreendedorismo Social da Enfermagem e Saúde - GEPESES.

${ }^{3}$ Enfermeiro. Especialista em Urgência, Emergência e Trauma. Mestrando em Enfermagem pelo Programa de Pós-Graduação em Enfermagem da Universidade Federal do Rio Grande - FURG. Bolsista CAPES. Membro do GEPESES.

${ }^{4}$ Enfermeira. Mestranda em Enfermagem pela FURG. Bolsista CAPES. Membro do GEPESES.

${ }^{5}$ Enfermeira. Mestre em Enfermagem. Doutoranda em Enfermagem pela FURG. Professora do Centro Universitário Franciscano. Membro do Grupo Interdisciplinar de Pesquisa em Educação e Saúde - GIPES.

${ }^{6}$ Enfermeira. Mestre em Educação. Professora do Curso de Graduação em Enfermagem do UNIFRA. Membro do GEPESES.
}

Autor correspondente:

Hilda Maria Barbosa de Freitas.

Centro Universitário Franciscano

Rua Felix Mainardi, 240 - 97110-633 - Santa Maria-RS-Brasil

E-mail: hildasame@gmail.com
Recebido: 07/12/2012 Aprovado: 09/09/2013 


\section{INTRODUÇÃO}

A Unidade de Terapia Intensiva (UTI) surgiu a partir da necessidade de aperfeiçoamento e concentração de recursos materiais e humanos para o atendimento a pacientes graves, em estado crítico, mas tidos como recuperáveis. Ainda, da necessidade de observação constante, assistência de enfermagem e médica contínua, centralizando os pacientes em um núcleo especializado ${ }^{(1)}$. Embora seja o local ideal para o atendimento a pacientes recuperáveis, a UTI parece ser um dos ambientes mais agressivos, tensos e traumatizantes do hospital. Estes fatores não atingem apenas os pacientes e a equipe multiprofissional, mas também, os familiares destes pacientes ${ }^{(2)}$.

Dessa forma, é necessário entender que o ser humano não está isolado, é parte de um todo, ou seja, ele se desenvolve em ambientes diferentes e com pessoas diversas que possuem bagagem cultural e social especifica. Neste contexto, a família, como extensão do paciente, deve ser incluída no seu plano terapêutico, requerendo comunicação efetiva com a equipe de enfermagem. A família trará grandes benefícios, tanto para o paciente e seus familiares, quanto para a equipe de saúde, uma vez que a comunicação contribuirá para um cuidado mais humanizado ${ }^{(3)}$.

Nesta perspectiva, a equipe de enfermagem que atua em UTI deve cuidar dos pacientes e seus familiares, dando-lhes conforto, ajudando-os na compreensão perante a vivência desta internação, que ainda é relacionada à morte iminente por muitas pessoas ${ }^{(1)}$. As diferentes formas de resposta a essa vivência demandam que a equipe esteja atenta, mostrando-se sensível às necessidades destes familiares, buscando caminhos efetivos para atendê-los ${ }^{(4)}$.

Em busca de cuidado de excelência, a equipe de enfermagem precisa considerar a singularidade e historicidade de cada paciente e seus familiares ${ }^{(5)}$. Assim, evidencia-se a necessidade de uma abordagem específica no atendimento dos familiares que permanecem do lado de fora dessas unidades, na expectativa de receber informações do quadro evolutivo do familiar internado, gerando situações de angústia e apreensão.

Com o intuito de melhorar o atendimento aos familiares, alguns hospitais têm implantado a visita aberta que consiste em dispositivo da Política Nacional de Humanização da Atenção e Gestão do Sistema Único de Saúde. A visita aberta dá ao paciente o direito de receber até cinco acompanhantes, um por vez, que são orientados quanto a importância da rede social de cada paciente no processo de tratamento, assim como sobre os horários e cuidados a serem observados durante as visitas ${ }^{(6)}$.

Estudo refere que a presença dos familiares junto ao paciente internado gera apoio e segurança, contribuindo para melhoria do cuidado prestado(7). A internação na UTI modifica a vida familiar em conjunto, pois restringe a proximidade dos familiares junto ao paciente ocasionando, muitas vezes, sofrimento. Esse sentimento pode ser amenizado pela possibilidade constante de a família estabelecer relações de troca e envolvimento com o paciente ${ }^{(8)}$.

Nesta perspectiva, evidencia-se a comunicação entre enfermeiro e familiar como importante ferramenta para manter a família informada sobre a realidade do paciente, explicar os procedimentos realizados, e os motivos da existência de determinadas regras e normas de conduta. Esta é uma ação que se revela, portanto, fundamental no envolvimento e participação do familiar nos cuidados. Neste contexto, o enfermeiro pode contribuir para amenizar os sentimentos de angústia, oferecendo apoio e suporte emocional necessário ao enfrentamento do processo vivido, sendo crucial para a redução do sentimento de medo, tanto dos pacientes quanto dos familiares ${ }^{(3)}$.

Com base no exposto questiona-se: quais são os sentimentos despertados em familiares de paciente internados na Unidade de Terapia Intensiva? Na tentativa de responder aos questionamentos anteriormente explicitados, objetivou-se conhecer os sentimentos despertados em familiares de pacientes internados na Unidade de Terapia Intensiva em relação ao ambiente e aos profissionais atuantes.

\section{MÉTODO}

Trata-se de uma pesquisa exploratória descritiva de caráter qualitativo ${ }^{(9)}$, desenvolvida na UTI de um hospital de médio porte localizado na região central do Rio Grande do Sul. Esta Unidade possui 10 leitos destinados à internação de pacientes adultos. Como critério de inclusão estabeleceu-se: ser familiar de paciente internado na UTI no período do estudo, formando o corpus deste estudo, as entrevistas a oito familiares de pacientes internados nesta unidade.

A coleta dos dados ocorreu nos meses de agosto e setembro de 2010 por meio da técnica de entrevista semiestruturada, contemplando questões abertas, com vistas a compreender os sentimentos despertados nos familiares frente a hospitalização. A análise de conteúdo se deu três momentos: o primeiro constituiu-se 
em uma frequência com identificação das principais percepções dos entrevistados em relação ao ambiente e aos profissionais atuantes na UTI; o segundo analisou o conteúdo identificando as categorias que emergiram a partir dos dados coletados; e o terceiro interpretou essas categorias, buscando compreender a vivência dos entrevistados, a partir da experiência dos pesquisadores, relacionando-a ao objetivo do estudo ${ }^{(10)}$.

Foram considerados os preceitos éticos e legais que envolvem a pesquisa com seres humanos, conforme Resolução 196/96 do Ministério da Saúde ${ }^{(11)}$. Manteve-se o anonimato dos depoentes e os mesmos foram identificados pela letra " $F$ " referente à Familiar, seguida de um algarismo numérico, conforme ordem de entrevista (F1, F2 ... F8). Em cumprimento as normas da resolução, o projeto de pesquisa foi aprovado pelo Comitê de Ética em Pesquisa do Centro Universitário Franciscano, sob o protocolo de número 181.2010.2.

\section{RESULTADOS}

Das oito entrevistas que foram realizadas com os familiares de pacientes internados em UTI adulto, quatro foram realizadas com os filhos, duas com as esposas, uma com a neta e uma com a prima. Salienta-se que todos os pacientes estavam internados há mais de dez dias. Dos dados coletados emergiram em quatro categorias, a seguir apresentadas.

\section{Impotência frente à hospitalização do familiar}

Os familiares entrevistados mostraram-se em conflito de sentimentos, devido à situação vivenciada, confusos pelo fato de seu familiar estar numa situação de fragilidade e vulnerabilidade, longe de todos os seus significantes, o que contribui para sentimentos de perda, abandono e outros, expresso nas falas a seguir:

Sentimento assim de, bah, pena, muita dó, não poder fazer nada né, CTI é complicado. Quando me falaram, que ela vinha transferida do outro hospital para a UTI me senti da pior maneira possivel, porque ela sempre foi uma mulher saudável. (F5)

Sinto como se tivesse sem uma parte de mim, ela que me criou, é mais mãe do que avó. (F8)

Um sentimento de impotência mediante o caso sentiame, como se não houvesse mais nada a fazer, e neste momento os sentimentos semisturaram medo, apreensão, insegurança. Mas, dentre os piores, o medo da perda. Acredito que enquanto seres humanos, não fomos preparados suficientemente para entender a perda. (F7)

[me sinto] muito mal, triste, agoniada. Minha mãe queria falar e não conseguia. Isso dói muito, não consigo esquecer. (F6)

Os dados mostram que os familiares se sentem comprometidos com o bem-estar do ente querido, mas impotentes pela situação adversa ao ambiente familiar onde gerenciavam esse cuidado. No âmbito hospitalar, essa situação fica fora do controle da família.

\section{Insegurança relacionada à proximidade com a morte}

A morte é um evento biológico que encerra uma vida, capaz de gerar sentimentos e reações emocionais, tanto no indivíduo que está enfermo como nos seus familiares. Nos relatos a seguir, torna-se evidente a relação da UTI com a morte na perspectiva dos familiares:

Quando me falaram que ele ia vir pra UTI, achei que ele já fosse morrer, porque sempre escuto isso, que quem entra aqui, é muito difícil sair vivo e bem. (F1)

Ele me diz que vai morrer, eu sei né, mas prefiro pensar que não. Tem noites que nem durmo, porque acordo pensando que já tenho que voltar correndo prá cá. (F3)

Mas sei lá, parece que nada me conforta, pode parecer fiasco para os outros, mas e se ela morrer, quem vai cuidar de mim? [choro] ela não pode ir!! (F6)

A UTI é compreendida pelos familiares como o último recurso antes da morte sendo importante que perceba este ambiente como um local de recuperação para a vida, e não de sua finitude.

\section{Inflexibilidade da equipe de saúde diante do familiar}

No atendimento aos familiares de pacientes internados na UTI percebe-se o despreparo da maioria dos profissionais que atuam nessa unidade. A sobrecarga de trabalho é um dos fatores responsáveis pela falta de orientação e acompanhamento dos familiares na sala de espera. Por conseguinte as falas:

Ali dentro, eles se preocupam tanto com o paciente, claro e devem, mas se esquecem da gente aqui fora. 
Os horários de visitas ficam na contra mão. Eu tô sempre fazendo plantão aqui prá ver se encontro com o médico. (F2)

Entendo que os médicos tenham os compromissos deles, mas então porque não marcar um horário com cada família pra dar maiores informações, ou porque ao menos um fique nos horários de visita pra falar com a família. Nunca se sabe direito como ele está, as enfermeiras só dão informações até por ali, não entendo. (F4)

Acho que deveria ter horários mais flexiveis, ou que desse pra entrar mais vezes por dia. Encontrar como médico, eu nunca consegui, parece que ele vem mais de noite. (F5)

Os horários poderiam ser mais compridos, se bem que eu mal consigo ficar lá dentro, não posso ver ela nesse estado, mas mesmo assim, só de saber que poderia vir mais vezes por dia, ficaria mais feliz. (F6)

As falas refletem o desafio dos profissionais de saúde, mais especificadamente de enfermeiros e médicos diante do cuidado do ser humano como um ser singular e integral. Assim, torna-se necessário um olhar diferenciado com relação aos familiares, no sentido de compreender a dimensão física, psíquica, social e espiritual, em que se encontram com a situação da internação de um ente querido. $\mathrm{O}$ respeito à singularidade e dignidade do ser humano vai além do cuidado técnico e prescritivo, envolve compromisso e valorização do ser humano como um todo.

\section{Ausência de diálogo com os familiares}

Nas falas dos entrevistados fica evidente a falta de acolhimento, comunicação e orientação dos profissionais com os familiares, resultando em insegurança, dúvidas e desentendimento por parte dos familiares:

Seria tão bom, se tivesse alguém aqui prá conversar com a gente, nem que fossem 10 ou 15 minutinhos antes das visitas, pra dar um apoio, falar alguma coisa boa, porque ficando aqui sozinha, eu escuto tanta gente que sai feliz dali, mas também tem uns que saem muito mal, e não tem ninguém aqui por nós. (F2)

Muita coisa poderia ser diferente no atendimento conosco, porque eles lá dentro tão bem cuidados, mas e aqui fora? Que atendimento que dão pra nós. (F4)

Em casa, parece que tudo tá descontrolado, uns tem uma opinião, querem que procure outro médico, mais especializado, outros querem outra coisa, e acaba que todo mundo briga com todo mundo, ninguém mais se entende. (F4)

É por meio da comunicação, do diálogo com a família que se consegue compreender sua história de vida, o modo de ser, de pensar, de agir, de aceitar a situação da hospitalização. A partir deste cuidado, será possível identificar fragilidades vivenciadas pelos familiares, auxiliando-os no enfrentamento e adaptação à doença e hospitalização do familiar na UTI.

\section{DISCUSSÃO}

A UTI é um ambiente destinado ao atendimento de pacientes graves, com risco de vida e que necessitam de cuidados de enfermagem e médicos ininterruptos. Os pacientes internados na UTI são submetidos à monitorização constante de suas funções orgânicas e a cuidados altamente complexos, na tentativa do restabelecimento do seu estado de saúde. É um ambiente caracterizado por uma constante expectativa de situações de emergência. Esses fatores tornam o ambiente estressante para todos que convivem e trabalham neste local ${ }^{(12)}$.

A maioria das admissões de pacientes na UTI necessita de intervenções rápidas. Em decorrência de um fazer imediato, muitas vezes, o contato inicial com o familiar fica em segundo plano, o que contribui para o entendimento da UTI como um local em que predomina a frieza e a atuação desumana e distante. Entretanto, considera-se que a interação com os familiares deve ser realizada desde o momento da internação, proporcionando-lhes atenção, oportunidade de dialogar e de esclarecer dúvidas ${ }^{(13)}$.

Não se deve esquecer que do lado de fora da UTI existe familiares, muitas vezes angustiados, que se sentem impotentes, em relação a doença e internação do paciente e que também se desorganizam com a doença, assustando-se com a possibilidade da morte $^{(14)}$. Os familiares também necessitam da atenção da equipe de saúde, e constituem uma força afetiva que pode e deve ser envolvida no cuidado ao paciente, pois muitas vezes, são fontes de motivação para enfrentar o sofrimento e virtualidade da morte.

Neste contexto, é de extrema importância que os enfermeiros exerçam e estimulem o acolhimento e 
orientação dos familiares de pessoas internadas na UTI, assumindo o papel de mediador entre o paciente e seus familiares, neste ambiente que geralmente é estressante para ambos. Assim, os enfermeiros devem flexibilizar a organização e dinâmica da unidade para que esse contato ocorra, sempre que possível, desde o momento da internação ${ }^{(15)}$.

Os familiares, inicialmente e de modo frequente, encontram-se fragilizados e angustiados frente à possibilidade da morte. Desta forma, antes de prestar assistência a estes, considera-se importante que cada membro da equipe de enfermagem reconheça suas próprias necessidades, limitações e potencialidades para poder compreender o outro ${ }^{(1)}$. Torna-se necessário reconhecer a singularidade do paciente e dos seus familiares, nesse momento particular da sua vida, respeitando sua condição humana.

Nesta circunstância é necessário um preparo contínuo, emergindo sensibilidade, empatia, com capacidade de tentar se colocar na situação do outro. Quando se adota esse modo de agir, amplia-se a receptividade e disponibilidade para escutar, tocar e dialogar ${ }^{(13)}$. Entretanto, a possibilidade de construir outros paradigmas, requer sensibilidade e disponibilidade para aprender o novo, capacidade para reconhecer a si mesmo e depois conhecer o outro e, principalmente, a crença de que os significados e afetos presentes na relação familiar são insubstituíveis para a melhoria e recuperação do paciente.

Em uma relação terapêutica, pacientes e familiares devem ser respeitados em sua individualidade, direitos e valores. $\mathrm{O}$ paciente precisa ser reconhecido como integrante de uma família, por isso, algumas considerações e cuidados devem ser centrados nos familiares, propiciando um clima acolhedor e de proximidade.

Essa interação necessita envolver a equipe de enfermagem, o paciente e seus familiares, considerando os aspectos físicos, emocionais, éticos, espirituais e sociais do cuidar ${ }^{(13)}$.

Mesmo quando os familiares se encontram em um estado de fragilidade emocional ou de crise, continuam ocupando papel de destaque para o paciente, contribuindo para que se sinta protegido, seguro, amado. Tais sentimentos, na maioria das vezes, o estimulam a lutar pela vida. Daí, a percepção da relevância da presença da família na UTI, seja para conversar com o paciente, tocá-lo ou simplesmente observá-lo, mesmo quando este se encontra inconsciente ${ }^{(13)}$.

Em algumas falas observou-se que a desestrutura familiar está presente, que todos adoecem em função do paciente internado. Este processo vai ao encontro dos laços familiares, das rotinas e da história de vida de cada paciente e sua família, as quais não podem passar despercebidas pela equipe de saúde. A situação de crise vivida pelos familiares pode ser observada pela desorganização das relações interpessoais e devido à distância física do paciente, a problemas financeiros e ao medo da perda do paciente.

Esse desequilíbrio, pode ainda ocorrer, pela diminuição do número de horas de sono, por distúrbio na alimentação e aumento no uso de ansiolíticos. Também, permeiam esse processo grande número de pensamentos e questionamentos sobre possíveis sequelas, estado geral e risco de morte do paciente ${ }^{(12)}$.

A equipe de saúde de UTI, por vezes acredita que o cuidado dos familiares depende, basicamente, de habilidades e características individuais, e que esta responsabilidade é exclusiva de profissionais específicos, como psicólogos e assistentes sociais. Entretanto, embora esses profissionais tenham extrema importância no processo, o cuidado dos familiares é de responsabilidade de todos na $\mathrm{UTI}^{(5)}$. Os enfermeiros e demais profissionais de saúde necessitam considerar os familiares como sujeitos expostos à desordem provocada pela internação do paciente, necessitando de informações e orientações constante ${ }^{(8)}$.

Devem se mostrar disponíveis e sensíveis aos familiares, investigando se possuem dúvidas, se já foram orientados corretamente, e o que desejam conhecer a respeito do cuidado, do tratamento e da própria rotina da $\mathrm{UTI}^{(8)}$. Neste contexto, o enfermeiro que muitas vezes assume liderança da equipe de saúde dessa unidade precisa, além de possuir habilidades técnico-científicas, compreender a importância dos familiares no processo de reabilitação dos pacientes, tornando flexível a presença do familiar neste ambiente.

\section{CONSIDERAÇÕES FINAIS}

O cuidado ao familiar do paciente internado em UTI é uma necessidade que deve se estender do desenvolvimento profissional para o cotidiano do serviço dos profissionais de que atuam neste ambiente. Contudo, na realidade investigada, esse não é realizado como esperados pelos familiares. $\mathrm{O}$ despreparo e a própria sobrecarga de trabalho são alguns dos fatores responsáveis pela falta de orientação e acompanhamento dos familiares, uma vez que a ênfase maior é para a saúde do paciente internado.

Evidenciou-se o conflito de sentimentos vivenciado pelos familiares, os mesmos encontram-se, por vezes, 
confusos pelo fato de seu familiar doente estar numa situação de fragilidade e vulnerabilidade e por estar na UTI, esse sentimento aparece potencializado, somado à proximidade da morte. Assim, torna-se necessário que os profissionais de saúde possuam, além de habilidades técnicas, um olhar diferenciado com relação aos familiares, no sentido de compreendê-los enquanto seres biopsicossociais que se encontram fragilizados e ansiosos com a situação da internação.

Neste contexto, o enfermeiro que normalmente assume a liderança das equipes da saúde deve buscar novas formas de compreender e exercer o cuidado, entendido como um fenômeno amplo e complexo. Sob esse enfoque, necessita estender o cuidado aos familiares, compreendendo como um processo dinâmico, possibilitando novas formas de organização que contemplem o cuidado, não apenas ao paciente, mas também aos familiares. A partir deste cuidado, será possível identificar fragilidades vivenciadas pelos familiares, auxiliando-os no enfrentamento e adaptação à doença e à hospitalização do familiar na UTI, bem como desmistificar a associação deste ambiente ao evento da morte.

\section{REFERÊNCIAS}

1. Sanches PG, Carvalho MDB. Vivência dos enfermeiros de unidade de terapia intensiva frente à morte e o morrer. Rev. Gaúcha Enferm. [Internet] 2009;30(2) [acesso em 20 jun 2010]. Disponível: http://seer.ufrgs.br/ RevistaGauchadeEnfermagem/article/view/3294/6687

2. Proença MO, Dell Agnolo CM. Internação em Unidade de Terapia Intensiva: percepção de pacientes. Rev. Gaúcha Enferm. [Internet] 2011;32(2) [acesso em 20 jun 2011]. Disponível: http://seer.ufrgs.br/ RevistaGauchadeEnfermagem/article/view/16953

3. Leite NC, Vasconcelos JMB, Fontes WD de. A comunicação no processo de humanização da assistência em Unidade de Terapia Intensiva: vivência de familiares e cuidadores. Rev. enferm. UFPE on line. [Internet] 2010;4(4) [acesso em 20 dez 2010]. Disponível: http:// www.revista.ufpe.br/revistaenfermagem/index.php/ revista/article/download/957/1559+\&cd $=1 \&$ hl $=$ pt$\mathrm{BR} \& \mathrm{ct}=\mathrm{clnk} \& \mathrm{gl}=\mathrm{br}$

4. Pina RZ, Lapchinsk LF, Pupulim JSL. Percepção de pacientes sobre o período de internação em unidade de terapia intensiva. Ciênc. cuid saude. [Internet] 2008;7(4) [acesso em 20 dez 2011]. Disponível: http://periodicos.uem. br/ojs/index.php/CiencCuidSaude/article/view/6658/3916
5. Soares M. Cuidando da família de pacientes em situação de terminalidade na unidade de terapia intensiva. Rev. bras. ter. intensiva. [Internet] 2007;19(4) [acesso em 5 mar 2010]. Disponível: http://dx.doi.org/10.1590/S0103507X2007000400013

6. Ministério da Saúde (BR). Hospital de Base de Brasília implanta "visita aberta". Distrito Federal. 2010, [acesso em 20 out 2010]. Disponível: http://portal.saude.gov.br/ portal/saude/visualizar_texto.cfm?idtxt $=31392$

7. Urizzi F, Correa AK. Relatives' experience of intensive care: the other side of hospitalization. Rev. Latino-Am. Enfermagem. [Internet] 2007;15(4) [acesso em 2 set 2013]. Disponível: http://dx.doi.org/10.1590/S010411692007000400012

8. Siddiqui S, Sheikh F, Kamal R. What families want an assessment of family expectations in the ICU. Int Arch Med. [Internet] 2011;4(21) [acesso em 3 set 2013]. Disponível: http://www.ncbi.nlm.nih.gov/pme/articles/ PMC3130654/pdf/1755-7682-4-21.pdf

9. Minayo MCS. O desafio do conhecimento: pesquisa qualitativa em saúde. $11^{\mathrm{a}}$ ed. São Paulo: Hucitec Abrasco; 2008.

10. Bardin L. Análise de conteúdo. $4^{\mathrm{a}}$ ed. Lisboa: Edições 70; 2009.

11. Ministério da Saúde (BR). Conselho Nacional de Saúde. Diretrizes e normas regulamentadoras de pesquisa envolvendo seres humanos. Resolução n. 196, de 10 de outubro de 1996. Brasília; 1996.

12. Urizzi F, Carvalho LM, Zampa HB, Ferreira GL, Grion CM, Cardoso LQ. Vivência de familiares de pacientes internados em unidade de terapia intensiva. Rev. bras. ter. intensiva. [Internet] 2008;20(4) [acesso em 20 mar 2010]. Disponível: http://dx.doi.org/10.1590/S0103507X2008000400009

13. Silveira RS, Lunardi VL, Lunardi WDF, Oliveira AMN. Uma tentativa de humanizar a relação da equipe de enfermagem com a família de pacientes internados na UTI. Texto Contexto Enferm. [Internet] 2005;15(n. esp.) [acesso em 20 mar 2010]. Disponível: http://dx.doi. org/10.1590/S0104-07072005000500016

14. Elisabete S, Felismina M. A partilha de informação com familiares em unidade de tratamento intensivo: importância atribuída por enfermeiros. Cogitare enferm. [Internet] 2011;16(2) [acesso em $20 \mathrm{dez} 2012$ ]. Disponível: http://ojs.c3sl.ufpr.br/ojs-2.2.4/index.php / cogitare/article/viewFile/21814/14224 
15. Pinho LB, Santos SMA. Dialética do cuidado humanizado na UTI: contradições entre o discurso e a prática profissional do enfermeiro. Rev Esc Enferm USP. [Internet] 2008;42(1) [acesso em $20 \mathrm{dez}$ 2008]. Disponível: http://dx.doi.org/10.1590/S008062342008000100009 